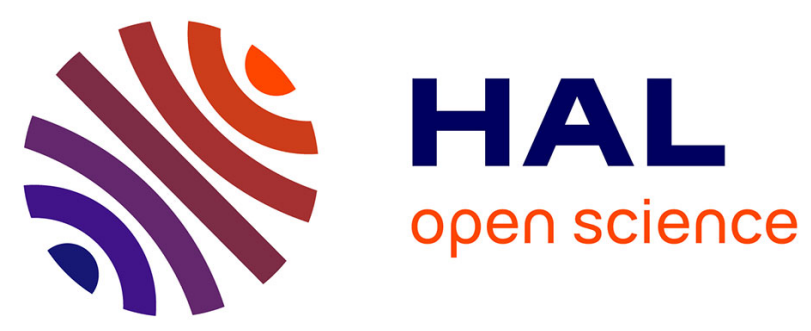

\title{
Reducing the hidden burden of severe asthma: Recognition and referrals from primary practice
}

Marc Humbert, Arnaud Bourdin, Nikolaos Papadopoulos, Stephen Holgate,

Nicola Hanania, David Halpin, Kenneth Chapman, Marcela Gavornikova, David Price, Alan Kaplan, et al.

\section{To cite this version:}

Marc Humbert, Arnaud Bourdin, Nikolaos Papadopoulos, Stephen Holgate, Nicola Hanania, et al.. Reducing the hidden burden of severe asthma: Recognition and referrals from primary practice. Journal of Asthma, 2020, 10.1080/02770903.2020.1759084 . hal-02559502

\section{HAL Id: hal-02559502 https://hal.science/hal-02559502}

Submitted on 4 Aug 2021

HAL is a multi-disciplinary open access archive for the deposit and dissemination of scientific research documents, whether they are published or not. The documents may come from teaching and research institutions in France or abroad, or from public or private research centers.
L'archive ouverte pluridisciplinaire HAL, est destinée au dépôt et à la diffusion de documents scientifiques de niveau recherche, publiés ou non, émanant des établissements d'enseignement et de recherche français ou étrangers, des laboratoires publics ou privés. 


\title{
Reducing the hidden burden of severe asthma: recognition and referrals from primary practice
}

\author{
Marc Humbert, MD ${ }^{\mathrm{a}, \mathrm{b}} \quad$, Arnaud Bourdin, $\mathrm{MD}^{\mathrm{c}}$, Nikolaos G. Papadopoulos, MD ${ }^{\mathrm{d}, \mathrm{e}}$, Stephen T. Holgate, $\mathrm{MD}^{\mathrm{f}}$, \\ Nicola A. Hanania, MD ${ }^{g}$, David M. G. Halpin, $\mathrm{MD}^{\mathrm{h}}$, Kenneth R. Chapman, MD', Marcela Gavornikova, MD ${ }^{\mathrm{j} *}$, \\ David B. Price, $M D^{k, I}$, Alan Kaplan, $M D^{m}$, and Liam G. Heaney, $M D^{n}$ \\ aUniversité Paris-Saclay, Faculté de Médecine, Le Kremlin-Bicetre, France; 'bervice de Pneumologie, Hôpital Bicêtre, Le Kremlin- \\ Bicêtre, France; 'Department of Respiratory Diseases, Université de Montpellier, PhyMedExp, INSERM, CNRS, CHU de Montpellier, \\ Montpellier, France; ${ }^{\mathrm{d}}$ Division of Infection, Inflammation \& Respiratory Medicine, The University of Manchester, Manchester, UK; ${ }^{\mathrm{e}}$ The

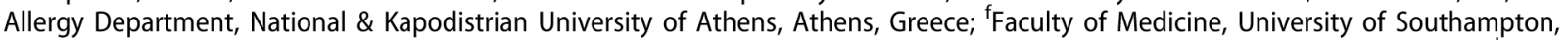 \\ Southampton, UK; ${ }^{9}$ Section of Pulmonary, Critical Care and Sleep Medicine, Baylor College of Medicine, Houston, Texas, USA; ${ }^{\mathrm{R}}$ Royal \\ Devon \& Exeter Hospital, Exeter, UK; 'Asthma and Airway Centre, University Health Network, and University of Toronto, Toronto,

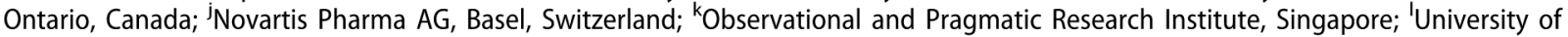 \\ Aberdeen, Aberdeen, UK; ${ }^{m}$ Family Physician Airways Group of Canada, University of Toronto, Toronto, Ontario, Canada; ${ }^{n}$ Centre for \\ Experimental Medicine, School of Medicine, Dentistry and Biomedical Sciences, Queen's University Belfast, Belfast, UK
}

\begin{abstract}
Since their introduction many decades ago, systemic corticosteroids have become a mainstay treatment for asthma. Despite being a highly effective therapy, corticosteroids can cause significant adverse effects in patients. This results in a "double hit" for some patients as they suffer the burden of disease as well as the burden of treatment-induced morbidity. This article aims to raise awareness of the potential, harmful side effects of prolonged or repeated exposure to systemic corticosteroids in asthma. It also highlights the importance of referral of the appropriate patients with asthma from primary care for specialist assessment once other considerations such as adherence, inhaler technique and co-morbidity have been evaluated. We propose a simple decision step that may help busy primary care physicians and general practitioners to identify patients who could benefit from specialist assessment.

Our decision step suggests that a patient with asthma should be reviewed at least once by an asthma specialist if he/she (i) has received $\geq 2$ courses of oral corticosteroids in the previous year; asthma remains uncontrolled despite good adherence and inhaler technique; or (ii) has attended an emergency department or was hospitalized for asthma care.

Such referral could facilitate wider access to diagnostic tools, in-depth assessment of confounding comorbidities, and non-corticosteroid-based therapies as needed, which may be unavailable in primary practice.
\end{abstract}

\section{KEYWORDS}

Systemic corticosteroids; referral; specialist; primary care; general practitioner; decision step process; noncorticosteroid therapy

\section{Introduction}

Chronic or repeated short courses of systemic corticosteroid therapy are commonly prescribed to people with asthma as maintenance therapy or for the treatment of asthma exacerbations (1). These may include patients with severe asthma, patients who are undertreated, patients with poor adherence to therapy, and patients with difficult-to-treat comorbidities (2). Despite the availability of highly effective therapies (3), it is estimated that approximately $5-10 \%$ of patients with asthma have severe disease which does not respond to standard of care medications and often requires systemic corticosteroid therapy (4). Although the prevalence of severe asthma is low (approximately $10 \%$ of the population), these patients contribute to about $50 \%$ the overall asthma-related healthcare cost $(5,6)$. In the USA, the total annual asthma cost was estimated to be \$USD 56 billion in 2011, which translates into an average annual cost of approximately \$USD 5,000 per patient, being much higher in patients with severe asthma (7). In the pediatric population, those with severe asthma $(\sim 5 \%)$ account for

CONTACT Marc Humbert $@$ marc.humbert@aphp.fr E Université Paris-Saclay, Faculté de Médecine, Service de Pneumologie, Hôpital Bicêtre, 78 Rue du Général Leclerc, 94270, Le Kremlin-Bicêtre, France.

* Marcela Gavornikova was an employee of Novartis Pharma AG at the time of manuscript initiation. 
half of the total healthcare cost (8). Therefore, severe asthma is both a clinical and an economic priority.

This manuscript focuses on the importance of timely referral of appropriate patients from primary care to specialists trained in the management of severe asthma when attempting to achieve asthma control as early as possible and minimizing need for systemic corticosteroids.

\section{Crucial role of the primary care physician in severe asthma}

In countries where most asthma is managed in primary practice, the primary care physician/general practitioner (GP/PCP) has a crucial task: to recognize asthma that is severe, and to explore the need for escalation of therapy beyond that available in primary practice, and then to refer the appropriate patients for specialist assessment (9).

Although only a minority of patients with asthma requires such referral, our clinical experience would suggest that simple, effective criteria (e.g.a decision step or algorithm) would be helpful for busy GPs/ PCPs, for referral of the appropriate patients in whom basic therapies, inhaler technique, adherence, triggers, and comorbidities have already been reviewed.

The Global Initiative for Asthma (GINA) outlines a general list of indications for referral to an asthma specialist. These include difficulty confirming a diagnosis of asthma, suspected occupational asthma, and risk factors for asthma-related death (3). GINA has also produced a report on the diagnosis and management of difficult-to-treat and severe asthma (3). Despite the existence of these recommendations, we believe that increased focus is needed on targeting referral to those patients with most to gain in terms of disease burden, which could potentially be improved by specialist assessment.

\section{Why does specialist referral not always occur for appropriate patients?}

We posit that there are several reasons why the appropriate patients are not always referred for specialist assessment:

i. Clinical inertia: Systemic and inhaled corticosteroids are usually effective in this chronic inflammatory disease (2), and are readily available for prescribing in primary care. Inhaled corticosteroids (ICS) have been shown to reduce asthma symptoms, exacerbations, hospitalizations, and to improve lung function (10). Short-term oral corticosteroid (OCS) courses are also highly effective in the treatment of acute exacerbations $(11,12)$.

Moreover, these therapies are relatively affordable in most countries, particularly when compared with expensive (and sometimes difficult-to-access) biologic treatments. However, the adverse effects associated with systemic corticosteroid treatments are an important consideration (13), and will be discussed further below. Associated with the cost of biologic treatments, insurance coverage might also act as a barrier both to medication access and with regards to the cost of a specialist referral. Other potential barriers include time, distance (geographical location) and availability.

ii. Primary care disease: We suggest that there has been a long-standing, common misconception that asthma is a "benign" disease $(13,14)$ that could be managed wholly in primary care, perhaps placing GPs/PCPs under pressure not to refer patients to specialists. Furthermore, it is known that patients tend to over-estimate their level of disease control vs. standard measures (e.g. Asthma Control Questionnaire) (15), and often tolerate symptoms to preclude taking medication (16), thereby compromising asthma control. The GP/PCP is in a key position to recognize these barriers to control. We believe that support and/or co-management from specialists, for certain patients, may help to overcome these barriers and reduce the future risk of exacerbation, impaired lung function, and potential side effects of systemic corticosteroid use.

iii. Lack of awareness: It is possible that the GP/PCP does not have the time to, or does not have the tools to, distinguish the clinical symptoms of asthma from other conditions or to assess inhaler technique, adherence and spirometry. This, among other factors, can lead to diagnostic uncertainty and under-diagnosis of this disease in patients with asthma (13).

GPs/PCPs, while aware of the significant adverse effects that are related to high-dose inhaled and even brief systemic corticosteroid treatment in asthma management, and may not be as aware of alternative therapies available beyond primary care. Mild ICSrelated side effects may include skin bruising or sore throat (17). Other adverse effects related to ICS use in 
patients with severe asthma include dose-dependent suppression of hypothalamic-pituitary-adrenal (HPA)-axis function, reduced growth velocity, and increased risk of diabetes and osteoporotic bone fractures (18). Furthermore, ICS use has been associated in a dose-related manner with infective complications, such as an increased risk of pneumonia and mycobacterial disease compared with non-ICS use (19).

Numerous adverse effects also occur with OCS use (20). In a recent study, patients who received at least one OCS prescription had a significantly higher risk of developing osteoporosis/osteoporotic fracture, pneumonia, cardio/cerebrovascular disease, cataracts, sleep apnea, renal impairment, depression/anxiety, type 2 diabetes mellitus, and weight gain compared with those without systemic steroid exposure (1). Furthermore, another study has shown that exposure to $\geq 4$ OCS prescriptions is associated with significantly greater risk of hypertension, obesity, and gastrointestinal ulcers/bleeds (21). These medicines are regularly used in pediatric patients also, and side effects remain highly relevant for this vulnerable population (22). A recent study reported a $17 \%$ increased risk of bone fracture in pediatric patients after only one OCS course, compared with none (23), highlighting the harmful effects of OCS use in children.

When side effects are considered, chronic use of high-dose ICS and/or repeated OCS courses is unlikely to be the most effective treatment option for all patients. Patients with severe asthma suffer not only asthma-related morbidity, but also face the morbidities related to chronic corticosteroid exposure.

There are a number of non-corticosteroid-based therapeutic options available to patients with severe or uncontrolled disease, e.g.leukotriene receptor antagonists, long-acting $\beta_{2}$-agonists, long-acting muscarinic antagonists, and allergen desensitization (immunotherapy). Biologic therapies have now become increasingly available for treatment of severe disease, with some only available outside of the primary care setting. The favorable safety profile of biologic therapies such as omalizumab (24-26), mepolizumab $(27,28)$, benralizumab (29,30), reslizumab (31), and dupilumab (32), compared with the known risks of the abovementioned steroid adverse effects, should remain an important consideration. Bronchial thermoplasty may also be a useful intervention in selected patients with severe asthma, although the selection of patient phenotypes most likely to benefit remains problematic and the procedure is not widely available (33). The known heterogeneity of asthma, including the existence of phenotypes and endotypes, underscores the need for deeper specialist-led characterization of patients with severe asthma. This supports the use of more targeted, effective therapies (5), where appropriate, whilst minimizing potential treatment-associated side effects.

\section{A simple decision step process for appropriate specialist referral}

From a practical perspective and as part of a multifaceted approach to asthma management, the importance of non-pharmacological endeavors should be emphasized in primary care, e.g.identifying and avoiding allergic triggers, occupational and environmental trigger avoidance, and smoking cessation (34). Although smoking cessation is important, an active smoking status should not be seen as a barrier to referral of a patient. Furthermore, comorbidities such as chronic rhinosinusitis with nasal polyps, chronic obstructive pulmonary disease, correct inhaler technique, and adherence to therapy should be evaluated and addressed in primary care before referring a patient for specialist assessment (Figure 1). Key steps before referral include:

- Re-affirm diagnosis

- Assess and treat comorbidities

- Review environment and triggers

- Review inhaler technique

- Assess adherence.

However, for patients who do not clinically improve in primary care despite these steps, we propose a specific decision step process in an effort to prompt consideration of a specialist referral:

A patient with asthma should be reviewed at least once by an asthma specialist if he/she:

- received $\geq 2$ courses of OCS in the preceding year; or

- has poor symptom control despite good adherence and inhaler technique; or

- attended an emergency department (ED), or was hospitalized for asthma care.

While two or more courses of OCS in the previous year is the proposed requirement for referral, even one OCS course in a patient who has been, thus far, optimally managed should be regarded as a suboptimal outcome of preventive therapy, and may prompt an investigation by the GP/PCP into the reasons for 


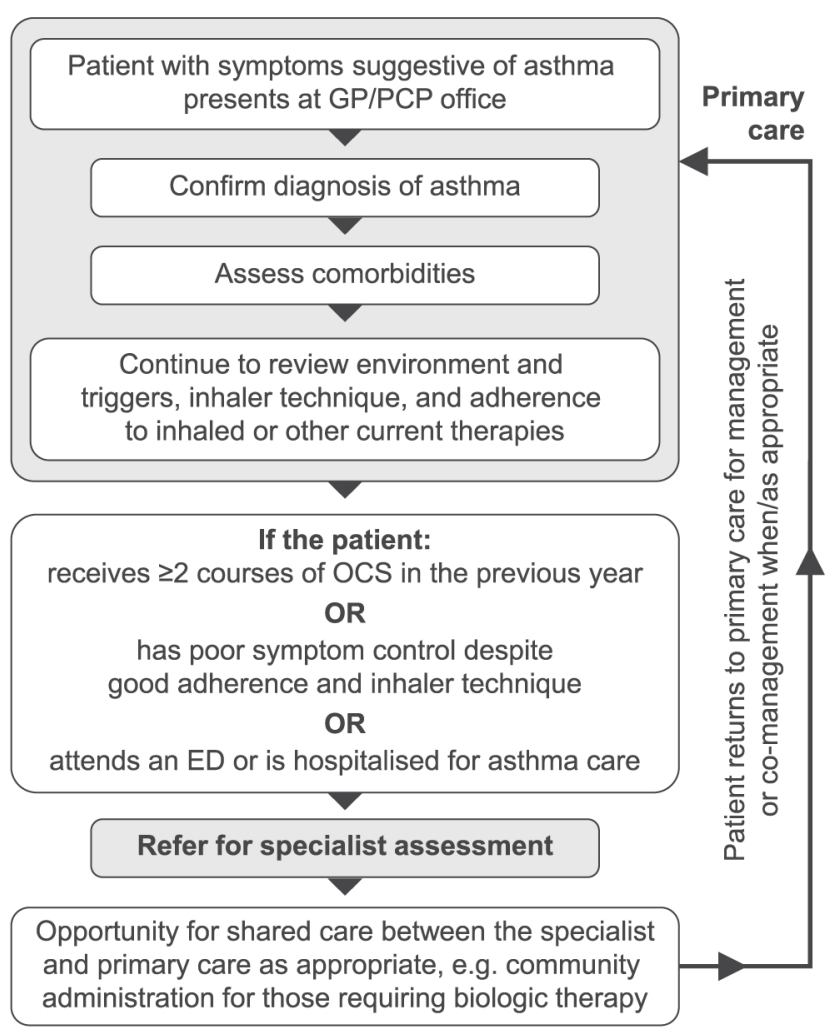

Figure 1: Decision step process for referral of appropriate patients with asthma for specialist assessment. ED: emergency department; OCS: oral corticosteroids.

this. Other instances where referral to a specialist may be considered are: atypical presentation of asthma or diagnostic ambiguity which needs further testing that cannot be performed in primary care; when potentially confounding or treatment-resistant comorbidities are present; when there are possible occupational causes; and when it involves patients who need escalation to a therapy that is unavailable in the primary care setting.

\section{Future considerations and concluding remarks}

Without specialist referral, access to potentially efficacious therapies such as biologics may be limited (13). Increasing the awareness of busy GPs/PCPs of the support that the specialist may offer in the management of certain patients may be beneficial. The need to use the suggested decision step in this article may ultimately vary from country to country depending on the local healthcare systems in place. However, we believe that implementation of such a decision step process in primary care will: (i) better support busy GPs/PCPs; (ii) increase the rate of specialist referrals for appropriate patients; (iii) provide an opportunity to improve access to efficacious biologic agents at an earlier stage; and (iv) reduce reliance on high-dose
ICS and repeated courses of OCS for patients with asthma.

Improving rates of referral for appropriate patients who are considered to have severe asthma will require a thoughtful review of healthcare delivery systems. For example, a collaborative care approach between the GP/PCP and the asthma specialist may reduce the number of patients requiring full referral to specialist care, allowing the patient to be co-managed in primary care with the benefit of shared expertise and a potential reduction in costs of referral.

The lack of continuity in healthcare delivery in some national healthcare systems is a $21^{\text {st }}$ century challenge. If GPs/PCPs have insight only into visit-byvisit issues and lack an overview of patient progress (including systemic steroids prescribed in urgent care settings by other practitioners), then increasing awareness of severe asthma and newly available treatments may have little impact on referrals. Indeed, advancing technologies may support such efforts, including the use of risk registers in primary care to identify patients with severe asthma who may benefit from referral for specialist assessment (35). For example, an automated system using GP/PCP electronic records to flag patients for referral, even if the patient presents in the primary care clinic for non-asthma reasons, may be useful. Furthermore, the development of severe asthma screening instruments, or the involvement of pharmacists or insurance companies to identify patients receiving multiple courses of OCS for asthma exacerbations, may also be helpful. Such a strategy becomes feasible with the use of a simple marker or decision step to highlight where referral needs to be considered, as we have described herein.

\section{Contributions}

All authors were involved in the conception, drafting, and critical review of this article. All authors approved the final version to be published and agree to be accountable for all aspects of this work.

\section{Disclosure statement}

Arnaud Bourdin reports personal fees from Novartis, Sanofi, Genentech, and Chiesi Farma; and grants and personal fees from GlaxoSmithKline, AstraZeneca, and Boehringer Ingelheim. Kenneth Chapman reports grants and personal fees from AstraZeneca, Boehringer Ingelheim, CSL Behring, Grifols, Sanofi, Genentech, Kamada, Roche, and Novartis; grants from Baxter, GlaxoSmithKline, and Amgen; personal fees from Merck and CIHR-GSK Research Chair in Respiratory Health Care Delivery, UHN. Marcela Gavornikova was a full-time employee of Novartis Pharma 
AG at the time of manuscript initiation. David Halpin reports personal fees and non-financial support from Novartis, GlaxoSmithKline, and Boehringer Ingelheim; and personal fees from AstraZeneca, Chiesi, and Pfizer. Nicola Hanania reports personal fees from Novartis, Sanofi, GlaxoSmithKline, AstraZeneca, and Genentech. He also reports grants through his institution from GlaxoSmithKline and AstraZeneca outside of the submitted work. Liam Heaney reports personal fees from Novartis, Roche/Genentech Inc., Sanofi, GlaxoSmithKline, Teva, Respivert, Merck Sharp and Dohme, AstraZeneca, Nycomed, Vectura, Boehringer Ingelheim, and Aerocrine. He also reports sponsorship to attend scientific meetings from AstraZeneca, Boehringer Ingelheim, GlaxoSmithKline, and Napp Pharmaceuticals. Vitalograph Ltd. provided INCA inhaler technology within the MRCfunded RASP-UK programme. Aerocrine AB facilitated reduced cost of Aerocrine FeNO machines within the MRCfunded RASP-UK programme. Stephen Holgate reports personal fees from Novartis and Synairgen. Marc Humbert reports personal fees from Novartis, AstraZeneca, GlaxoSmithKline, Roche, Sanofi, and Teva. Alan Kaplan reports personal fees from AstraZeneca, Boehringer Ingelheim, GlaxoSmithKline, Novartis, Pfizer, Purdue, Teva, Trudel, Mylan, Sanofi, and NovoNordisk; grants from Benton Dickinson and Trudel; and non-financial support from GlaxoSmithKline, Novartis, Pfizer, MD Briefcase, and Sea Cruises. Nikolaos Papadopoulos reports consultancy or speaker fees from Novartis, Menarini, Hal Allergy B.V., and Mylan. He also reports grants from Gerolymatos. David Price reports grants to his institution and personal fees from Aerocrine, AstraZeneca, Boehringer Ingelheim, Chiesi, Mylan, Mundipharma, Napp, Novartis, Pfizer, Regeneron Pharmaceuticals, Sanofi Genzyme, Teva, Theravance, and Zentiva (Sanofi Generics). He reports personal fees from Almirall, Amgen, Cipla, GlaxoSmithKline, Kyorin, Merck, and SkyePharma, and grants to his institution from AKL Research and Development Ltd., the British Lung Foundation, Respiratory Effectiveness Group, and the UK National Health Service. David Price has stock/stock options in AKL Research and Development Ltd., which produces phytopharmaceuticals, and owns $74 \%$ of the social enterprise Optimum Patient Care Ltd (Australia and UK) and 74\% of Observational and Pragmatic Research Institute Pte Ltd (Singapore). He is peer reviewer for grant committees of the Efficacy and Mechanism Evaluation programme, and Health Technology Assessment.

\section{Funding}

Medical writing support was provided by Gillian Lavelle, $\mathrm{PhD}$, and Ian Wright, $\mathrm{PhD}$, of Novartis Product Lifecycle Services, Dublin, Ireland, funded by Novartis Pharma AG, Basel, Switzerland, in accordance with Good Publication Practice (GPP3) guidelines (http://www.ismpp.org/gpp3).

\section{References}

1. Price DB, Trudo F, Voorham J, Xu X, Kerkhof M, Ling Zhi Jie J, Tran TN. Adverse outcomes from initiation of systemic corticosteroids for asthma: longterm observational study. JAA. 2018;11(11):193-204. doi:10.2147/JAA.S176026.

2. Volmer T, Effenberger T, Trautner C, Buhl R. Consequences of long-term OCS therapy and its side effects in severe asthma in adults - A focused review of the impact data in the literature. Eur Respir J. 2018;52(4):1800703. doi:10.1183/13993003.00703-2018.

3. Global Initiative in Asthma. Diagnosis and management of difficult-to-treat and severe asthma. Available from http://ginasthma.org/gina-reports/ [last accessed on 23 September 2019].

4. Chung KF, Wenzel SE, Brozek JL, Bush A, Castro M, Sterk PJ, Adcock IM, Bateman ED, Bel EH, Bleecker ER, et al. International ERS/ATS guidelines on definition, evaluation and treatment of severe asthma. Eur Respir J. 2014;43(2):343-373. doi:10.1183/09031936. 00202013.

5. Trevor JL, Chipps BE. Severe Asthma in Primary Care: Identification and Management. Am J Med. 2018; 131(5):484-491. doi:10.1016/j.amjmed.2017.12.034.

6. World Allergy Organization (WAO). Economic Analysis of the Cost of Treatments for Severe Asthma. Available from: http://www.worldallergy.org/ educational_programs/world_allergy_forum/anaheim2005/ blaiss.php [last accessed 15 March 2019].

7. Nunes C, Pereira AM, Morais-Almeida M. Asthma costs and social impact. Asthma Res Pract. 2017;3:1. doi:10.1186/s40733-016-0029-3.

8. Chipps BE, Bacharier LB, Farrar JR, Jackson DJ, Murphy KR, Phipatanakul W, Szefler SJ, Teague WG, Zeiger RS. The pediatric asthma yardstick: Practical recommendations for a sustained step-up in asthma therapy for children with inadequately controlled asthma. Ann Allergy Asthma Immunol. 2018;120(6): 559-579. doi:10.1016/j.anai.2018.04.002.

9. Yawn BP, Wechsler ME. Severe asthma and the primary care provider: identifying patients and coordinating multidisciplinary care. Am J Med. 2017; 130(12):1479. doi:10.1016/j.amjmed.2017.10.001.

10. Reddel HK, Busse WW, Pedersen S, Tan WC, Chen Y-Z, Jorup C, Lythgoe D, O'Byrne PM. Should recommendations about starting inhaled corticosteroid treatment for mild asthma be based on symptom frequency: a post-hoc efficacy analysis of the START study. Lancet. 2017;389(10065):157-166. doi:10.1016/ S0140-6736(16)31399-X.

11. Similowski T, Suissa S. Systemic steroids in severe forms of COPD exacerbations: a question of balance?. Eur Respir J. 2014;43(3):668-670. doi:10.1183/09031936. 00000214.

12. Rowe BH, Keller JL, Oxman AD. Effectiveness of steroid therapy in acute exacerbations of asthma: a metaanalysis. Am J Emerg Med. 1992;10(4):301-310. doi: 10.1016/0735-6757(92)90007-K.

13. Price D, Bjermer L, Bergin DA, Martinez R. Asthma referrals: a key component of asthma management 
that needs to be addressed. JAA. 2017;10:209-223. doi:10.2147/JAA.S134300.

14. Suissa S, Ernst P, Benayoun S, Baltzan M, Cai B. Low-dose inhaled corticosteroids and the prevention of death from asthma. N Engl J Med. 2000;343(5): 332-336. doi:10.1056/NEJM200008033430504.

15. Menzies-Gow A, Chiu G. Perceptions of asthma control in the United Kingdom: a cross-sectional study comparing patient and healthcare professionals' perceptions of asthma control with validated ACT scores. NPJ Prim Care Respir Med. 2017;27(1):48. doi:10. 1038/s41533-017-0050-x.

16. Bidad N, Barnes N, Griffiths C, Horne R. Understanding patients' perceptions of asthma control: a qualitative study. Eur Respir J. 2018;51(6): 1701346. doi:10.1183/13993003.01346-2017.

17. Papi A, Brightling C, Pedersen SE, Reddel HK. Asthma. Asthma. Lancet. 2018;391(10122):783-800. doi:10.1016/S0140-6736(17)33311-1.

18. Heffler E, Madeira LNG, Ferrando M, Puggioni F, Racca F, Malvezzi L, Passalacqua G, Canonica GW. Inhaled Corticosteroids Safety and Adverse Effects in Patients with Asthma. J Allergy Clin Immunol Pract. 2018;6(3):776-781. doi:10.1016/j.jaip.2018.01.025.

19. Brode SK, Campitelli MA, Kwong JC, Lu H, Marchand-Austin A, Gershon AS, Jamieson FB, Marras TK. The risk of mycobacterial infections associated with inhaled corticosteroid use. Eur Respir J. 2017;50(3):1700037. doi:10.1183/13993003.00037-2017.

20. Miloslavsky EM, Naden RP, Bijlsma JW, Brogan PA, Brown ES, Brunetta P, Buttgereit F, Choi HK, DiCaire JF, Gelfand JM, et al. Development of a Glucocorticoid Toxicity Index (GTI) using multicriteria decision analysis. Ann Rheum Dis. 2017;76(3): 543-546. doi:10.1136/annrheumdis-2016-210002.

21. Sullivan PW, Ghushchyan VH, Globe G, Schatz M. Oral corticosteroid exposure and adverse effects in asthmatic patients. J Allergy Clin Immunol. 2018; 141(1):110-116. doi:10.1016/j.jaci.2017.04.009.

22. Hossny E, Rosario N, Lee BW, Singh M, ElGhoneimy D, Soh JY, Le Souef P. The use of inhaled corticosteroids in pediatric asthma: update. World Allergy Organ J. 2016;9:26. doi:10.1186/s40413-0160117-0.

23. Gray N, Howard A, Zhu J, Feldman LY, To T. Association Between Inhaled Corticosteroid Use and Bone Fracture in Children With Asthma. JAMA Pediatr. 2018;172(1):57-64. doi:10.1001/jamapediatrics.2017.3579.

24. Pelaia C, Calabrese C, Terracciano R, de Blasio F, Vatrella A, Pelaia G. Omalizumab, the first available antibody for biological treatment of severe asthma: more than a decade of real-life effectiveness. Ther Adv Respir Dis. 2018;12:175346661881019. 1753466618810192. doi:10.1177/1753466618810192.

25. Incorvaia $C$, Mauro M, Makri E, Leo G, Ridolo E. Two decades with omalizumab: what we still have to learn. BTT. 2018;12:135-142. doi:10.2147/BTT.S180846.
26. Long A, Rahmaoui A, Rothman KJ, Guinan E, Eisner M, Bradley MS, Iribarren C, Chen H, Carrigan G, Rosen $\mathrm{K}$, et al. Incidence of malignancy in patients with moderate-to-severe asthma treated with or without omalizumab. J Allergy Clin Immunol. 2014; 134(3):560-567. doi:10.1016/j.jaci.2014.02.007.

27. Ortega HG, Liu MC, Pavord ID, Brusselle GG, FitzGerald JM, Chetta A, Humbert M, Katz LE, Keene ON, Yancey SW, Chanez P. Mepolizumab treatment in patients with severe eosinophilic asthma. N Engl J Med. 2014;371(13):1198-1207. doi:10.1056/ NEJMoa1403290.

28. Pavord ID, Korn S, Howarth P, Bleecker ER, Buhl R, Keene ON, Ortega H, Chanez P. Mepolizumab for severe eosinophilic asthma (DREAM): a multicentre, doubleblind, placebo-controlled trial. Lancet. 2012;380(9842): 651-659. doi:10.1016/S0140-6736(12)60988-X.

29. Bleecker ER, FitzGerald JM, Chanez P, Papi A, Weinstein SF, Barker P, Sproule S, Gilmartin G, Aurivillius M, Werkstrom V, et al. Efficacy and safety of benralizumab for patients with severe asthma uncontrolled with high-dosage inhaled corticosteroids and long-acting beta2-agonists (SIROCCO): a randomised, multicentre, placebo-controlled phase 3 trial. Lancet. 2016;388(10056):2115-2127. doi:10.1016/ S0140-6736(16)31324-1.

30. FitzGerald JM, Bleecker ER, Nair P, Korn S, Ohta K, Lommatzsch M, Ferguson GT, Busse WW, Barker P, Sproule S, et al. Benralizumab, an anti-interleukin-5 receptor alpha monoclonal antibody, as add-on treatment for patients with severe, uncontrolled, eosinophilic asthma (CALIMA): a randomised, double-blind, placebo-controlled phase 3 trial. Lancet. 2016;388(10056): 2128-2141. doi:10.1016/S0140-6736(16)31322-8.

31. Murphy K, Jacobs J, Bjermer L, Fahrenholz JM, Shalit Y, Garin M, Zangrilli J, Castro M. Long-term Safety and Efficacy of Reslizumab in Patients with Eosinophilic Asthma. J Allergy Clin Immunol Pract. 2017;5(6):1572-1581. doi:10.1016/j.jaip.2017.08.024.

32. Castro M, Corren J, Pavord ID, Maspero J, Wenzel S, Rabe KF, Busse WW, Ford L, Sher L, FitzGerald JM, et al. Dupilumab Efficacy and Safety in Moderate-toSevere Uncontrolled Asthma. N Engl J Med. 2018; 378(26):2486-2496. doi:10.1056/NEJMoa1804092.

33. Heaney LG, McGarvey LP. Personalised Medicine for Asthma and Chronic Obstructive Pulmonary Disease. Respiration. 2017;93(3):153-61. doi:10.1159/000455395.

34. Gautier C, Charpin D. Environmental triggers and avoidance in the management of asthma. JAA. 2017; 10:47-56. doi:10.2147/JAA.S121276.

35. Smith JR, Noble MJ, Musgrave S, Murdoch J, Price GM, Barton GR, Windley J, Holland R, Harrison BD, Howe $A$, et al. The at-risk registers in severe asthma (ARRISA) study: a cluster-randomised controlled trial examining effectiveness and costs in primary care. Thorax. 2012;67(12):1052-1060. doi:10.1136/thoraxjnl2012-202093. 